\title{
Hanseníase: um caso bem-sucedido de intervenção terminológica?
}

DOI: http://dx.doi.org/10.21165/el.v50i2.2954

\author{
Márcia de Souza Luz-Freitas ${ }^{1}$ \\ Pâmela Teixeira Ribeiro²
}

\section{Resumo}

Não há, no Brasil, uma política linguística geral para o léxico especializado; no entanto, há ações glotopolíticas isoladas e uma delas foi a orientação terminológica para a denominação da patologia hanseníase (lepra). Com o objetivo de analisar as condições sociodiscursivas de uso das unidades lexicais especializadas relativas a essa doença, este trabalho fundamenta-se em teorias de viés comunicativo e linguístico da Terminologia, principalmente na Teoria Comunicativa da Terminologia (TCT). O corpus é composto por 250 artigos científicos publicados entre as décadas de 1970 e 2020 no Brasil. A produção científica brasileira sobre a hanseníase é vasta e a análise mostra que, embora determinadas unidades lexicais tenham seu uso restringido por lei, elas continuam a ser empregadas em contextos específicos. Conclui-se que, no caso específico da hanseníase, a iniciativa de planificação linguística teve efeito, mas não gerou o desuso da forma concorrente.

Palavras-chave: terminologia; política linguística; hanseníase.

1 Universidade Federal de Itajubá (UNIFEI), Itajubá, Minas Gerais, Brasil; marcialf@unifei.edu.br; https://orcid.org/0000-0002-7085-3047

2 Universidade de São Paulo (USP), São Paulo, São Paulo, Brasil; pamela.tribeiro@gmail.com; https://orcid.org/0000-0001-9148-5637 


\title{
Leprosy: a successful terminological intervention case?
}

\begin{abstract}
In Brazil, there is no general linguistic policy for the specialized lexicon. However, there are isolated glotopolitical actions, and one of them was the terminological guidance for leprosy (leprosy). The analysis of the sociodiscursive conditions of specialized lexical units related to this disease is based on terminological theories developed with a communicative and a linguistic bias, such as the Communicative Theory of Terminology (TCT). The corpus consists of 250 scientific papers published between the 1970s and 2020 in Brazil. The Brazilian scientific production on leprosy is vast. The analysis shows that, although specific lexical units have their use restricted by law, they continue to be used in specific contexts. The conclusion is that, in the particular case of leprosy, the linguistic planning initiative had an effect but did not generate the disuse of the concurrent form.
\end{abstract}

Keywords: Terminology; linguistic policy; leprosy.

\section{Considerações iniciais}

O estabelecimento de nomenclaturas e terminologias institucionais tem sido uma prática habitual em Ciências da Saúde. Nessa área, a necessidade de domínio do discurso especializado e da publicização de seus significados não só é imprescindível, por uma questão de preservação da vida e de controle de riscos, como também é elemento essencial para a gestão de dados relativos à saúde mundial e para a elaboração de programas de saúde pública. Assim, os estudos terminológicos dessa área dão suporte também para outras áreas, como a Administração Pública, a Economia e a Engenharia.

Várias instituições dependem direta ou indiretamente, em seu trabalho, da organização terminológica e criam seus próprios produtos terminográficos para consulta e troca de informações em saúde. No cenário internacional, citam-se: a Organização Mundial da Saúde(OMS), que coordena e mantém programas e projetos que envolvem desde questões de saneamento e higiene a situações epidemiológicas, e tem grande responsabilidade quanto à elaboração nosográfica internacional; e a Agência GMDN, responsável pela elaboração da Nomenclatura Global de Dispositivos Médicos (Global Medical Device Nomenclature - GMDN), que, dentre outras ações, fornece informações para compra e venda de produtos para saúde (equipamentos médicos, insumos, produtos para análise in vitro, implantáveis, entre outros.) No cenário nacional, cita-se a Agência Nacional de Vigilância Sanitária (ANVISA), que tem como objetivo realizar a regulação, o registro e a comercialização dos produtos para saúde dentro do território brasileiro.

A prática terminológica em Ciências da Saúde acompanha o desenvolvimento científico e tecnológico da área, como se pode perceber pelas organizações citadas, por exemplo, 
na identificação, na nomeação e na descrição de doenças e agentes etiológicos, bem como no desenvolvimento e na classificação de medicamentos e de equipamentos de diagnóstico e de tratamento das mais diversas patologias. Dada a abrangência da área, pode-se vislumbrar uma interseção de vários campos do saber, em que se destacam, com mais visibilidade, Medicina, Biologia, Bioquímica e Engenharia Biomédica.

Como qualquer avanço científico e tecnológico, o desenvolvimento das Ciências da Saúde e, consequentemente, de seus estudos terminológicos, emerge de um contexto sóciohistórico e cultural que influencia e define as escolhas linguísticas. Desse modo, ainda que se proceda a classificações que objetivem a unicidade e a equivalência de termos nesse discurso especializado, principalmente no tocante à atuação de organismos internacionais, a flutuação e a variação terminológica são inevitáveis.

A pesquisa relatada neste artigo surge no âmbito de um protocolo de cooperação celebrado entre a Universidade Federal de Itajubá (UNIFEI), em parceria com a Universidade de São Paulo (USP), a ANVISA e a Agência GMDN. O protocolo foi estabelecido com o propósito de identificar variantes terminológicas entre o Português Europeu (PE) e o Português Brasileiro (PB), tanto para os termos designativos de Produtos para saúde quanto para suas definições constantes do Banco de Dados GMDN.

No decorrer dessa identificação, alguns termos foram categorizados como variações heteronímicas, categoria criada para agrupar todos os termos que, do ponto de vista formal, se constituem por unidades lexicais distintas em PE e em PB. Um desses casos, que demandou maior tempo de análise, foi o par lepra/hanseníase. Na versão em PE do Banco de Dados GMDN, o termo lepra é utilizado para designar a patologia nas definições de alguns produtos para saúde utilizados em seu tratamento. Ao fazer uma busca nessa versão do Banco de dados em PE, não há ocorrência do termo hanseníase.

No Brasil, onde se estuda a viabilidade da implementação desse Banco de dados, com vistas à adoção de um sistema de identificação única de produtos para saúde, utilizase, tanto na prática cotidiana quanto em documentos oficiais, o termo hanseníase. Ao mesmo tempo, o termo lepra não é desconhecido no PB, e essa relação foi a motivação para esta pesquisa.

O objetivo deste artigo é analisar, em uma perspectiva diacrônica, as condições sociodiscursivas em que as unidades lexicais especializadas (ULE) relativas à doença hanseníase são empregadas em artigos científicos, ao longo dos anos 1970 a 2020.

A análise é fundamentada nas Ciências do Léxico, sobretudo na Terminologia. Uma vez definida a análise das ULE sob uma perspectiva discursivo-pragmática, cabe ressaltar que o estudo se desenvolve com prioridade para a Teoria Comunicativa da Terminologia - 
TCT (CABRÉ, 1999), que propõe a análise dos termos em contextos reais de uso. Também se mostraram necessários alguns fundamentos da Socioterminologia (BOULANGER, 1995; GAUDIN, 1993, 2014), com o enfoque da Terminologia como um meio para a implantação de políticas linguísticas de harmonização terminológica e da Terminologia Cultural (DIKI-KIDIRI, 1999, 2009), que considera aspectos socioculturais para o estudo da implantação da Terminologia em uma sociedade. Discorre-se sobre essas escolhas para o embasamento teórico do artigo na seção precisamente intitulada Fundamentação Teórica.

Consideram-se, assim, as condições de produção linguística e as situações de uso dos termos a partir do contexto social, cultural e histórico que os legitima. Dados gerais sobre a doença e sobre esse contexto são apresentados na seção intitulada Hanseníase: que mal é esse?

O delineamento metodológico é analítico-descritivo. O corpus é constituído de publicações científicas coletadas digitalmente em diacronias preestabelecidas. Delineamento metodológico e corpus são pormenorizados na seção Metodologia.

Os principais resultados e a discussão que eles proporcionaram são apresentados na seção Resultados e Discussão. Na sequência, sob o título Considerações finais, apresentamse as conclusões acerca da discussão empreendida.

\section{Fundamentação teórica}

A normalização sempre foi uma questão pertinente aos estudos terminológicos. Wüster, em sua tese de doutoramento intitulada A normalização internacional da terminologia técnica e publicada em 1931, já demonstrava sua preocupação com a padronização terminológica. O autor apresentava reflexões sobre a terminologia de sua área de estudo, a eletrotécnica, e propunha mecanismos de eliminação de problemas na comunicação científica por meio da monovalência, ou seja, pela univocidade entre conceito e termo (WÜSTER, 1998). Sua tese e suas reflexões posteriores à publicação da tese estabeleceram as bases da Escola Terminológica de Viena e permitiram a elaboração da Teoria Geral da Terminologia (TGT).

Como bem lembra Cabré (1999, p. 43, tradução nossa ${ }^{3}$ ), "a terminologia surge da necessidade manifestada pelos especialistas de ordenar as denominações de seus sistemas de conceitos, a fim de alcançarem uma comunicação profissional mais confiável". Porém, os instrumentos reguladores têm função padronizadora e normatizadora, o que

3 No original: "la terminologia nace de la necesidad manifestada por los especialistas de ordenar las denominaciones de sus sistemas de conceptos, con la finalidad de conseguir una comunicación profesional más fiable". 
pode parecer conflituoso ao se pensar que a língua é dinâmica, ao passo que as normas são estáticas.

Entreas críticas tecidas à TGT a partir demeados da década de 1980, está o questionamento da visão idealista de Wüster acerca dessa univocidade entre conceito e termo. Para Faulstich (1998), a normalização terminológica insere-se dentro do quadro genérico da normalização linguística. Entretanto, ao apresentar princípios da Socioterminologia (GAUDIN, 2003 apud FAULSTICH, 1998), a autora distingue normalização terminológica de normalização técnica e destaca o papel dos fatores históricos, geográficos, sociais e econômicos nas diferentes comunidades linguísticas. Em oposição à proclamada univocidade, surge o reconhecimento da existência da variação terminológica.

Cabré (1999), ao formular os fundamentos epistemológicos da Teoria Comunicativa da Terminologia (TCT), propõe justamente a valorização e a descrição dos aspectos linguísticos e das situações comunicativas de uso das unidades terminológicas, que deve preceder às questões da normalização. Cabré (2004) salienta que o funcionamento das unidades terminológicas extrapola os limites da comunicação especializada, pois seu uso depende do contexto linguístico, cultural e discursivo em que se produzem.

No entanto, ao mesmo tempo em que se observa o crescimento das abordagens descritivas, com enfoque linguístico, acerca da Terminologia, não se pode negar que as entidades normalizadoras e classificatórias têm assumido relevante papel na dinâmica da organização do conhecimento e, consequentemente, na elaboração de materiais lexicográficos e terminográficos. Pode-se afirmar que os esforços empreendidos na normalização não deixam de evidenciar uma prática social de linguagem. Essas práticas específicas, denominadas de "engenharia linguística", ou "planejamento linguístico" ou ainda "política linguística", são, segundo Spolsky (2009), resultantes de escolhas.

Sem pretensão de adentrar essa inconstância terminológica, neste trabalho opta-se pelo termo "política linguística", o mais frequente na literatura brasileira sobre o tema (SILVA, 2013). O termo refere-se a qualquer ação ou conjunto de ações ou intervenção estatal cujo objetivo é a gestão da língua ou das línguas faladas em determinado território. Para Rajagopalan (2008, p. 135), a política linguística, por natureza prescritiva e interventora, é dirigida à escrita, e "qualquer repercussão na forma oral da língua ocorre como consequência". Infere-se, portanto, que toda política linguística é uma prática social de linguagem que tem como principal função regular outras práticas sociais de linguagem.

Guespin e Marcellesi (1986) ampliam a noção de intervenção nas práticas sociais de linguagem ao cunharem o termo "glotopolítica". Para os autores, as agências glotopolíticas não se limitam ao Estado, mas englobam também outros agentes institucionais com poder para introduzir modificações e criar possibilidades de normatização e de normalização linguísticas. 
Auger (1993) afirma que a normalização linguística tem a função específica de modelar o comportamento dos usuários de uma língua. De tal modo, normalizar uma língua é propiciar situações comunicativas para que um determinado uso se torne normal.

É perceptível, assim, que há uma tensão entre normalização e língua em uso, o que acaba gerando, explícita ou implicitamente, mecanismos para contornar alguns impasses. Por exemplo, em relação a fenômenos linguísticos como a variação terminológica e a sinonímia, se, por um lado, para a padronização, tornam-se necessárias as indicações de termo preferido, termo equivalente ou correspondente, termo admitido e termo obsoleto (ISO 1087, 2000; ISO 15225, 2010), por outro lado, a dimensão discursivo-textual das práticas comunicativas revela movimentos de assimilação e de diferenciação no uso dos termos, tanto em relação à escolha lexical quanto à atribuição de sentidos.

Explicando a dimensão discursivo-textual na Terminologia, Krieger (2001, p. 29) afirma que "o exame das terminologias envolve também as categorias da textualidade e da discursividade para dar conta de seus modos de constituição e de funcionamento". Lino et al. (2010, p. 188-189) assim explicam esse novo enfoque:

Esta nova abordagem textual, designada de Terminologia textual, assim como a descrição dos fenómenos de variação em contexto constituem uma transgressão aos princípios clássicos da terminologia wüsteriana que privilegiava a tríade termo/conceito/referente, preconizando a monossemia do termo científico e técnico. Em consequência destas novas perspectivas e das novas propostas da Socioterminologia e da Terminologia Cultural, a nossa investigação incide, hoje, sobre a neologia terminológica, a metáfora terminológica, os vários tipos de variação terminológica aos quais se associam aspectos de lexicultura, presentes em muitos neônimos e termos científicos. Todos estes fenômenos linguísticos têm uma grande incidência na descrição terminológica, na lexicografia de especialidade, na tradução eno ensino-aprendizagem das línguas de especialidade.

Nessa perspectiva, os termos não são apenas unidades lexicais especializadas, mas também unidades discursivas. Uma análise pautada em textos, que são frutos de situações discursivo-comunicativas concretas, deve abordar as condições de produção dos textos que constituem o corpus bem como os fenômenos linguísticos nele observáveis. Há que se considerar também, como bem explica Cabré (1999), que as unidades terminológicas podem ocorrer em diferentes níveis de especialização, ou seja, em diferentes textos especializados.

Gläser (1982) classifica os textos especializados em cinco tipos: a) textos acadêmicocientíficos e textos tecnológicos, como monografias e artigos científicos, caracterizados pelo alto grau de abstração; b) textos de divulgação científica, com grau médio de abstração, que são dirigidos a um público mais amplo, como as revistas de divulgação; 
c) textos didáticos, com função educativa e instrucional, como manuais e livros escolares; d) textos injuntivos, com função instrucional e, muitas vezes, legislativa, como contratos e leis; e) textos de comunicação cotidiana com algum caráter informativo ou explicativo. Hoffmann (1998) propõe quatro critérios para a classificação dos textos especializados: o âmbito comunicativo e temático, o nível de especialização, o canal de comunicação e o tipo de tratamento dado ao tema. Para Freixa (2002, p. 137), em Terminologia, "a existência de diferentes níveis de especialização é atualmente um fato assumido".

Ciapuscio (2003) propõe uma tipologia de multiníveis, que congrega os níveis funcional, situacional, formal-gramatical e de conteúdo semântico. O nível funcional compreende as funções textuais, em um total de quatro funções básicas: expressar-se, contatar o interlocutor, informar e direcionar ações. O nível situacional diz respeito à modalidade da comunicação, ao espaço e ao tempo em que essa se realiza e à competência comunicativa dos interlocutores envolvidos. O nível formal-gramatical refere-se às marcas linguísticas da superfície do texto, aos recursos gramaticais, sintáticos e lexicais e à estilística. No nível de conteúdo semântico, enquadram-se os aspectos temáticos e as sequências tipológico-textuais.

Desse modo, não podemos pensar em um único tipo de texto especializado, mas em um número bem mais amplo de textos especializados. Não podemos pensar também em um conjunto terminológico formado apenas por unidades lexicais especializadas, mas sim em um modo de dizer específico de cada área do conhecimento e para cada intencionalidade do gênero técnico-científico produzido.

Sobre a criação de termos e terminologias e sua implantação em determinada prática especializada de uma sociedade, Diki-Kidiri $(1999,2009)$ defende, sob o ponto de vista das línguas africanas, que uma abordagem cultural da Terminologia é essencial para o desenvolvimento das línguas em geral, de modo que essas sejam instrumentalizadas para expressarem a realidade do mundo moderno. De acordo com o autor, qualquer língua é apta a se expressar cientificamente (DIKI-KIDIRI, 1999). Considerando o fato de que o desenvolvimento das ciências e da Terminologia aconteceu principalmente na Europa e na América do Norte, criou-se a necessidade de os países de língua africana serem inseridos nesse contexto científico. O autor pondera que, para que ocorra a inclusão de uma terminologia pronta em uma sociedade, é importante rever a abordagem terminológica de modo a contemplar aspectos culturais dos países que recebem terminologias prontas e, por meio do conhecimento das realidades desses países, propor terminologias representativas. Nessa perspectiva, o autor propõe um questionamento terminológico de modo a instrumentalizar as línguas africanas "para torná-las capazes de expressar realidades modernas, em particular aquelas que não existiam ou não eram preponderantes no mundo africano ancestral tradicional" (DIKI-KIDIRI, 1999, p. 61). 
Essa reflexão trazida pela Terminologia Cultural também se faz importante quando se considera a realidade do Brasil frente à patologia em questão. 0 país sofreu e ainda sofre muito com essa doença. Conhecer esse histórico e seus dados faz compreender a necessidade identificada pelos especialistas ao formularem uma nova proposta terminológica. Essa trajetória está traçada na sessão a seguir.

\title{
Hanseníase: que mal é esse?
}

Partindo-se dos aspectos lexicográficos, buscou-se o apoio dos dicionários de língua comum e de especialidades.

O Grande Dicionário Houaiss da Língua Portuguesa, em sua versão on-line (HOUAISS, 2009), define doença como "alteração biológica do estado de saúde de um ser manifestada por um conjunto de sintomas perceptíveis ou não; enfermidade, mal, moléstia". Ainda segundo esse dicionário, a palavra teria surgido na Língua Portuguesa, no século XIII, mesma época em que informa o surgimento da palavra mal com o sentido de "doença, enfermidade" (vigésima primeira acepção). Nessa acepção, encontra-se uma divisão em que se lê que mal tem também o sentido de hanseníase: "21.1 (1911) Brasileirismo; informal. Hanseníase". É interessante observar que há um indicativo de data para essa significação, em que, por um processo metonímico, a palavra mal designa um tipo específico de doença. O Michaelis Dicionário Brasileiro de Língua Portuguesa (MICHAELIS, 2015), na décima acepção para o verbete mal, aponta tal significação como um regionalismo do Rio Grande do Sul. O Dicionário Aulete (AULETE DIGITAL, 2008) também aponta o significado hanseníase, na nona acepção apresentada para mal, como um brasileirismo da região Sul, mas apenas na descrição original do verbete; não há tal significação na descrição do verbete atualizado. ${ }^{4}$

Hanseníase é definida nesses dicionários de modo semelhante. As definições foram elaboradas por meio da identificação do tipo de doença, sua causa, algumas de suas características e a indicação de outros possíveis nomes. Assim, tem-se hanseníase como

\begin{abstract}
[...] uma doença infecciosa crônica causada por Mycobacterium leprae ou bacilo de Hansen, que se inicia, após uma incubação muito lenta, por pequenas manchas despigmentadas onde a pele é insensível e não transpira e evolui para a forma tuberculosa (a mais comum), lepromatosa ou ainda intermediária; lepra. (HOUAISS, 2009).
\end{abstract}

4 Optou-se, neste estudo, exclusivamente por dicionários de língua geral on-line, ainda que alguns deles tenham versão impressa. Detalhes em itálico, negrito ou aspas nas citações ao longo do trabalho respeitam os textos originais. 
[...] infecção crônica, contagiosa, causada pelo Mycobacterium leprae, ou bacilo de Hansen, que produz inicialmente manchas sem pigmentos na pele, tornando-a insensível e sem transpiração, evoluindo para lesões mais graves nas mucosas e nos nervos periféricos; elefantíase dos gregos, gafa, gafeira, gafo, guarucaia, lazeira, lepra, leprose, macota, macutena, mal, mal-bruto, mal de cuia, mal de lázaro, mal de são lázaro, mal do sangue, mal-morfético, morfeia. (MICHAELIS, 2015).

[...] doença contagiosa, causada pelo bacilo de Hansen (Mycobacterium leprae), que provoca diversas feridas na pele e lesões em nervos periféricos; LEPRA (AULETE DIGITAL, 2008).

Como destacam Dores e Toledo (2018), em análise do verbete no Dicionário Houaiss, essas definições apresentam algumas características técnicas, como a indicação do nome científico do agente causador da patologia, embora estejam em dicionários não especializados.

O Dicionário de termos técnicos de medicina e saúde (REY, 2012) traz uma entrada do termo simples seguida de quatro entradas de termos compostos tendo hanseníase como elemento-base. Em todas as cinco entradas, a palavra vem seguida da expressão "[ou lepra]". A definição da primeira entrada, também elaborada por meio da identificação do tipo de doença e sua causa, traz uma série de informações em estilo enciclopédico. No final do verbete, lê-se:

Sinon.: lepra, mal de Hansen. [Nota: O nome oficial desta doença no Brasil é "hanseníase" e assim foi adotado pelas versões em português do DeCS e CID10; entretanto, na literatura médica internacional, inclusive na NID, segue sendo usado o nome "lepra"; lepra (espanhol), lèpre (francês), leprosy (inglês) etc.] ${ }^{5}$ (REY, 2012, p. 431).

Devido à origem eponímica, consultou-se também o Dicionário brasileiro de epônimos em medicina (COSTEIRA, 2010), em que se lê:

HANSEN, mal de. lepra; hanseníase; infecção granulomatosa crônica, causada pelo Mycobacterium leprae (bacilo de Hansen) e que acomete as partes mais frias do corpo, tais como a pele. Gerhard Henrik Armauer Hansen, médico norueguês (1841-1912).

5 Conforme a lista de abreviaturas da obra (REY, 2012, p. XV e XVI): Sinon. - Sinonímia ou nome comum; DeCS - Descritores em Ciências da Saúde (BIREME); CID-10 - Classificação Estatística Internacional de Doenças e Problemas Relacionados à Saúde, em sua décima revisão; NID Nomenclatura Internacional de Doenças (CIOMS/OMS). 
A versão em Língua Portuguesa da CID-10 para uso no Brasil (FSP-USP, 2008) é de responsabilidade do Centro Brasileiro de Classificação de Doenças (CBCD), mantido pela Faculdade de Saúde Pública (FSP) da Universidade de São Paulo (USP) ${ }^{6}$. Seguindo a formatação do original em inglês, ela faz uso de um termo preferencial seguido dos correspondentes entre colchetes. Diferentemente, porém, do original, o termo preferencial, na entrada principal A30, não é o correspondente lepra, mas sim hanseníase. Entre colchetes são colocados os termos sinônimos, doença de Hansen e lepra. As subdivisões da entrada apresentam a palavra lepra entre colchetes logo após a palavra hanseníase.

Esse aparente excesso terminológico justifica-se por uma questão legal e histórica. 0 Brasil, no início do século XX, chegou a ser exemplo nas Conferências Internacionais sobre lepra pela aplicação ferrenha do modelo norueguês de combate à doença, que se pautava na segregação dos doentes (OPROMOLLA, 2007; PANDYA, 2003; MDH, 2017). Mesmo com o término paulatino do isolamento compulsório, entre as décadas de 1960 e 1970, o estigma da doença, reforçado pelos mecanismos brutais da segregação, impedia o sucesso das novas políticas de profilaxia. Considerando que grande parcela do problema estava justamente na representação social que a semântica dos termos evocava, o Ministério da Saúde publicou a Portaria Ministerial BSB n 165, de 14 de maio de 1976, que definia nova terminologia a ser adotada pelo Ministério para a doença (MURAD, 1991).

Antes disso, um grupo de médicos especializados na doença já lutava pela mudança terminológica, o que levou à publicação da Deliberação SS/CTA n 7 , no Diário Oficial do Estado de São Paulo, em 11 de dezembro de 1970, e do Decreto nº 10.040, em 25 de julho de 1977. Opromolla e Laurenti (2011, p. 200) relatam:

Em 1970, o termo "lepra" e derivados foram abolidos oficialmente na terminologia oficial da Secretaria da Saúde do Estado de São Paulo. Essa medida proposta pelo Prof. Abraão Rotberg foi corroborada pelo então secretário de Saúde do Estado de São Paulo, Dr. Valter Leser, e pelo comitê técnico desse órgão, que publicou uma resolução determinando a criação de novo vocábulo para classificar essa doença. Desde então, a doença passou a denominar-se oficialmente "hanseníase" para a SES de São Paulo.

Finalmente, em decorrência dos trâmites do Projeto de Lei nº 1.624 (MURAD, 1991), o uso do termo lepra e de todos seus derivados em documentos oficiais foi proibido pela Lei no 9.010 (BRASIL, 1995).

6 Segundo informações do site (http://www.fsp.usp.br/cbcd/index.php/quem-somos/), "O CBCD foi, de 1976 a 2016, o Centro Colaborador da Organização Mundial da Saúde para a Família de Classificações Internacionais em Português. Suas atividades como Centro Colaborador da OMS cessaram no final de março de 2016". 
Os dicionários consultados fazem referência à carga semântica negativa do vocábulo lepra: "4 (Fig.) qualquer coisa cujos efeitos perniciosos e contagiosos são comparáveis aos da lepra. 5 (Fig.; Bras., Sul). pessoa má, imprestável." (HOUAISS, 2009); "4 (Fig.) Vício ou qualquer outro mal moral que afeta as pessoas e se propaga como essa doença. 5 (Reg. Sul) (Fig.) (Pej.) Pessoa má." (MICHAELIS, 2015); "4 (Fig.) Qualquer coisa que se propaga como a lepra. 5 (Bras. Sul) (Fig.) Pessoa imprestável, ruim." (AULETE DIGITAL, 2008, verbete atualizado) e "(Fig.) Diz-se de qualquer hábito vicioso e asqueroso que se propaga por várias pessoas ou classes. ॥ (Bras., Sul) (Pop.) Pessoa imprestável, ruim." (AULETE DIGITAL, 2008, verbete original). No entanto, nenhum deles faz qualquer referência ou comentário quanto à restrição de uso desse vocábulo.

Não há, no Brasil, uma política linguística definida quanto ao léxico especializado. 0 percurso histórico da implantação do termo hanseníase, porém, é um registro peculiar de uma ação glotopolítica explícita. É mister salientar que se tem a implantação de um neologismo, construído a partir do antropônimo Hansen ${ }^{7}$, a que se agregou o sufixo -íase, equivalente ao sufixo -ase, formador de substantivos que indicam estado. Com relação a esse tipo de formação, Alves (2006, p. 32) mostra que "de maneira análoga aos neologismos da língua geral, os neologismos terminológicos são formados pelos processos vernaculares da derivação, da composição, da transferência semântica, das formações sintagmáticas, da redução e pelo empréstimo de outros idiomas".

O Brasil foi pioneiro na designação da doença por meio de um substantivo derivado do referido antropônimo. Os demais países parecem continuar adotando denominação originária do latim lepra, ae, ou, como alternativa, a forma composta a partir de elemento nuclear correspondente ao vocábulo português mal usando-se o antropônimo como elemento periférico. Como Portugal utiliza o termo lepra, é esse o termo que consta na versão em Português Europeu da GMDN. Há que se ressaltar que, conforme aponta Di Dio (2000) existe um movimento para a eliminação de epônimos nas Ciências Biológicas e da Saúde, com vistas a simplificar e uniformizar a terminologia. A última versão oficial da terminologia anatômica, base da terminologia médica, já atende a essa reivindicação.

\section{Metodologia}

Em consonância com o que foi exposto e considerando que não existe um único tipo de texto especializado (GLÄSER, 1982; FREIXA, 2002; CIAPUSCIO, 2003), buscou-se selecionar textos que se enquadravam na categoria de textos acadêmico-científicos e textos tecnológicos, como monografias e artigos científicos, caracterizados pelo alto grau

7 Gerhard Henrick Armauer Hansen, médico bacteriologista norueguês, conhecido pela identificação do bacilo Mycobacterium leprae como o agente causador da "lepra" em 1873 e por defender o isolamento das pessoas infectadas (INTERNATIONAL LEPROSY ASSOCIATION, 2017; GRZYBOWSKI; KLUXEN; PÓLTORAK, 2014). 
de abstração. Também os critérios propostos por Hoffman (1987) citados anteriormente se observam no âmbito desta pesquisa, a saber:

1) âmbito comunicativo e temático: publicações científicas sobre o tema da hanseníase;

2) nível de especialização: textos redigidos por especialistas em nível de pósgraduação;

3) canal de comunicação: revistas e publicações científıcas;

4) tipo de tratamento dado ao tema: investigativo e descritivo.

A pesquisa documental foi essencial para este estudo, que utiliza corpora formados por 250 textos, coletados por meio do Google Acadêmico, plataforma que reúne publicações de literatura científica verificadas. Para a recolha desses textos com um mesmo grau de especialização e na diacronia definida (1970-2020), o Google Acadêmico mostrouse uma base de dados relativamente eficiente. Essa plataforma é um banco de dados virtual de pesquisa de textos completos ou metadados da literatura acadêmica em uma extensa variedade de formatos de publicação. Lançada em 2004, inclui a maior parte de revistas e livros on-line revisados por pares, artigos de conferência, pré-impressões, teses e dissertações, resumos, relatórios técnicos e outras literaturas acadêmicas, entre elas, pareceres de tribunais e patentes. O tamanho do banco de dados não é divulgado pela empresa, que tem sido criticada por não vetar publicações e incluir, em seu índice, revistas predatórias. Mesmo assim, esse mecanismo de busca de textos de literatura acadêmica foi utilizado, por ser aberto, gratuito, de fácil manuseio e oferecer a possibilidade de coletar um número significativo de artigos escritos em décadas anteriores.

Os corpora compreenderam, portanto, artigos científicos e textos monográficos elaborados em programas de pós-graduação brasileiros. Deu-se exclusividade a textos escritos já que se concorda, neste trabalho, com Rajagopalan (2008) que afirma que a política linguística, por ser prescritiva e interventora, é dirigida à escrita. Foi fundamental o recorte de textos científicos já que, para a publicação em periódicos científicos, é necessária a revisão por pares, e assim seria possível acompanhar diacronicamente a introdução e a adesão, pelos especialistas, a um termo artificial.

O critério de disponibilidade em ambiente virtual foi o primeiro a ser definido para que o processamento dos textos fosse facilitado. Também foram critérios na coleta de artigos científicos para a composição do corpus:

a) realização de busca no Google Acadêmico, com a palavra-chave hanseníase entre aspas, em páginas em português, em cinco períodos distintos: 1970-1979, 1980-1989, 1990-1999, 2000-2009 e 2010-2020;

b) exclusão de ocorrências que incluíam registros de patentes. 
Os resultados foram acessados de acordo com o parâmetro do Google para ordenação por relevância, que apresenta os documentos em ordem decrescente de citações. Foram selecionados, para cada década, os 50 primeiros documentos que tinham versão em extensão pdf disponível. Foram criadas planilhas para cada período específico, em que os documentos foram referenciados de acordo com as normas da ABNT e salvos com nome específico para remeter ao arquivo coletado em formato pdf. Com o auxílio do programa Wondershare PDF element Pro ${ }^{8}$, o material foi convertido para arquivos de extensão txt. Com esses arquivos, foram compostos 5 corpora para extração de dados por período.

Para o processamento, utilizou-se o software $A n t C o n c^{9}$, versão 3.5.8. A intenção foi estabelecer uma relação do conjunto vocabular pertinente para observar as situações de uso e a relação temporal, já que o movimento para a elaboração da legislação que determinou nacionalmente a terminologia da doença teve início na década de 1970.

Com os corpora sincrônicos estabelecidos de modo numericamente comparável, foram buscados os termos hanseníase e lepra para verificação de sua ocorrência em textos altamente especializados e análise diacrônica dos contextos de uso.

\section{Resultados e discussão}

A produção científica brasileira sobre hanseníase é bastante alta, tendo inclusive surgido um periódico específico: a revista Hansenologia Internationalis ${ }^{10}$. Tal fato pode ser interpretado como decorrência de um reflexo da realidade. O Brasil tem um alto índice da doença e apresenta dificuldades em atingir a meta de diminuição de casos proposta pela OMS (REYES, 2013). Ao número alto de doentes soma-se o estigma que a doença carrega ao longo da história, como se vê no excerto do corpus transcrito a seguir (Excerto 1).

\footnotetext{
8 O Wondershare PDF element Pro é um pacote de opções para leitura, edição, conversão e compartilhamento de documentos no formato PDF. O acesso é possível pela compra de assinatura semestral na página eletrônica https://www.wondershare.net/.

9 Esse utilitário foi desenvolvido pelo Professor Laurence Anthony da Faculdade de Ciência e Engenharia da Universidade Waseda (Japão) e está disponível para download em http://www. laurenceanthony.net/software/antconc/.
}

10 Página eletrônica do periódico: http://hi.ilsl.br/conteudo.php?pag=5. 
1. Tudo leva a crer, portanto, que os enfermos do Brasil (3 a 4 em cada 1.000 habitantes), da América Latina, Estados Unidos, Espanha e Portugal, bem como seus milhões de familiares, deverão continuar sofrendo o injusto e milenar <estigma da "lepra"> (enquanto perecem as atividades preventivas dessas áreas), a fim de que não pereça a caridade de alguns países, visando a outros países. Prevalecerão as superstições e as lendas, bem como as noções falsas de incurabilidade e extrema contagiosidade da moléstia, aterrorizando o público, envergonhando e ostracizando o paciente e assegurando seu ocultamento dos serviços de saúde. (28 - ROTBERG1975, p. 302).

Assim, é que, na intenção de analisar a dimensão discursivo-textual das ocorrências do termo hanseníase, deparou-se com a questão do estigma, o ponto-chave para o movimento de substituição da terminologia, que culminou com a publicação da lei no 9.010 (BRASIL, 1995). Ressalta-se que o artigo $1^{\circ}$ dessa lei diz que "o termo 'Lepra' e seus derivados não poderão ser utilizados na linguagem empregada nos documentos oficiais da Administração centralizada e descentralizada da União e dos Estados-membros" (grifo nosso).

A substituição impositiva, caracterizada como uma ação glotopolítica explícita, foi uma iniciativa de planificação linguística de grande efeito. Isso pode ser comprovado pela frequência crescente do termo hanseníase, nas publicações científicas, paralelamente ao decréscimo da frequência do termo lepra, o que revela que, na esfera acadêmicocientífica, a legislação conseguiu interferir na normalização linguística (Quadro 1). Podese justificar essa normalização ao se levar em consideração que:

a) médicos sanitaristas e cientistas brasileiros lideraram o movimento de alteração terminológica e muitos deles são os responsáveis pela produção dos textos da primeira sincronia analisada (1970-1979);

b) por se tratarem de textos científicos de alta especialização, que exigem nível linguístico formal e, consequentemente, grande rigor normativo, é esperado que os autores usem a terminologia oficialmente autorizada.

Quadro 1. Número de ocorrências dos termos

\begin{tabular}{|c|c|c|}
\hline Período & Hanseníase & Lepra \\
\hline $1970-1979$ & 455 & 365 \\
\hline $1980-1989$ & 775 & 88 \\
\hline $1990-1999$ & 1.963 & 205 \\
\hline $2000-2009$ & 2.349 & 221 \\
\hline $2010-2020$ & 2.727 & 162 \\
\hline
\end{tabular}

Fonte: Elaboração própria 
Entretanto, ainda que lepra e unidades lexicais derivativas sejam excluídas dos textos oficiais, esses termos podem ser empregados em contextos distintos em textos de outras esferas, inclusive a acadêmica. Por isso, a incidência de lepra, mesmo em comportamento de redução, se mantém.

No corpus da primeira sincronia, além dos contextos em que se questiona o estigma da doença, ainda se vê o uso de lepra como termo preferido, embora já se admita a concorrência (Excerto 2). Essa é a única sincronia que apresenta o registro do novo termo entre parênteses ao lado do anterior. O contrário não foi observado. Há, desse modo, uma oscilação entre o "velho" e o "novo". Lepra aparece como palavra-chave em vários artigos.

2. Os esteres do óleo de chalmoogra e hidnocarpo cujas origens de emprego remontam aos séculos passados, foram as medicações mais frequentemente empregadas contra a <lepra, (hanseníase)> até o advento das sulfonas, em 1941. (4 - OPROMOLLA1972, p. 12)

Uma das situações de uso bastante encontrada na sincronia 1980-1989 é a retomada histórica, em que se faz uso de lepra, seja em breves narrativas históricas na contextualização da problemática (Excerto 3), seja em nomes de entidades institucionais ou de eventos. Nessa sincronia, observa-se que, junto à substituição da terminologia, também se pode perceber a existência de ações públicas para o controle e o tratamento da doença (Excerto 4). É em 1981 que surge o Movimento de Reintegração das Pessoas Atingidas pela Hanseníase (MORHAN). Essa instituição teve grande importância na conquista da promulgação da Lei 9.010 (BRASIL, 1995).

3. Idêntica é a posição de Brubaker: "Assim vemos os portugueses introduzirem a <lepra> no que é hoje o Brasil, enquanto que sua importação no resto da América do Sul, América Central, México, a região do Caribe e sul dos Estados Unidos é atribuída aos espanhóis (em algumas partes também aos franceses e holandeses). Mais tarde, os escravos africanos trouxeram ao Novo Mundo não só a <lepra> como também população suscetível" Terra, 1925 referia que em 1696, o Governador do Rio de Janeiro procurava dar assistência aos doentes de <hanseníase>, então já em grande número. (10 - Belda1981, p. 26).

4 Portanto, procurou-se identificar os conhecimentos do pessoal de enfermagem sobre <hanseníase> para, posteriormente, analisar a assistência prestada pelos mesmos junto aos pacientes inscritos no Subprograma de Controle da <hanseníase>. (40 PEDRAZZANI1984, p. 45).

Na sincronia 1990-1999, ainda se observa o uso de lepra em narrativas históricas e nomes de entidades institucionais. Outras situações que se podem observar são o fato de lepra aparecer como palavra-chave para a indexação do artigo em bases internacionais, como 
termo nos resumos escritos em língua espanhola, bem como em citações e referências de materiais consultados. Esses últimos contextos de uso são encontrados também nas sincronias posteriores. Constata-se que se tornam marcas linguísticas características de uma produção científica mais sólida, que busca atender aos padrões internacionais.

O excerto 5 exemplifica a proliferação do conjunto vocabular da hanseníase, fenômeno comum na sincronia 2000-2010, conforme os destaques entre chevrons. É durante essa sincronia que as políticas públicas se tornam mais difundidas, apesar de o país não conseguir cumprir a meta da OMS.

5. Vinte e quatro por cento dos pacientes apresentaram <reações hansênicas> no tratamento e 9,0\% no pós-alta da forma Dimorfa. Verificou-se que 62,0\% dos <pacientes hansênicos> tinham contatos intradomiciliares com história de <hanseníase>; 20\% dos doentes tinham os pais portadores da enfermidade de formas multibacilares (principalmente Virchowianos); cerca de $20,0 \%$ eram os avós e $18,0 \%$ referiam-se à $<$ hanseníase > contraída pelos tios; $71 \%$ dos contatos intradomiciliares foram examinados durante o tratamento do doente e 19,0\% após a alta. Cerca de 10,0\% dos contatos não foram avaliados conforme as recomendações do <Programa de Hanseníase>. Somente em $15,5 \%$ dos contatos intradomiciliares do < portador de hanseníase > foram verificadas as duas cicatrizes da vacina BCG, preconizadas pelo <Programa de Hanseníase>. (24 FERREIRA, 2005, p. 5).

A última sincronia analisada traz algumas ocorrências de lepra na fala de pessoas entrevistadas (Excerto 6). Vários artigos usam entrevistas como ferramenta de coleta de dados, o que foi interpretado como o surgimento de novas metodologias ou sua diversificação nas pesquisas desenvolvidas nessas datas, e que o estigma se mantém no imaginário de um grupo de pessoas.

6. Por mais pânico que o ex-paciente de hanseníase possa ter em relação ao estigma e preconceito decorrentes da doença, muitas vezes surge a sensação de não saber aquilo que os outros estão realmente pensando dele. Muitas vezes, sente-se exposto e sem ter como reagir a olhares dúbios: Às vezes em casa quando ia parente eu ficava escutando eles dizerem assim: "Meu compadre, minha comadre, essa menina tem essa doença, <lepra>, né?! " (Ana) (19 - MARTINS, 2010, p. 1052).

Desde a primeira sincronia, observa-se a presença da palavra leprostigma. Formada por um processo de composição, ela é mais um neologismo cuja autoria é atribuída ao médico A. Rotberg, o mesmo criador do termo Hanseníase.

Paralelamente à constatação da necessidade de estandardização em domínios prioritários como as ciências da saúde, o dinamismo da língua define a diversidade discursiva. A implantação de uma política linguística para a hanseníase não tornou o termo lepra obsoleto, e pode ter reforçado seu caráter depreciativo. 


\section{Considerações finais}

Este trabalho teve como objetivo investigar uma questão que foi levantada durante uma pesquisa entre as variantes terminológicas entre PE e PB no âmbito das Ciências da saúde. Ao notar-se que o termo hanseníase não constava do Banco de dados do GMDN em PE e que os equivalentes em inglês também não faziam menção a esse termo, buscou-se investigar o caminho que foi tomado pelo Brasil na designação da doença.

Durante esta investigação, percebeu-se um empenho muito forte de alguns médicos de referência que consideraram que a intervenção política para mudança na terminologia da doença era fundamental para a diminuição do estigma e do preconceito contra os pacientes acometidos pela referida moléstia. Essa crença foi tão eficaz que esse grupo movimentou o Congresso Nacional e conseguiu a aprovação de uma lei que trata somente dessa terminologia e que define a hanseníase e seus derivados como termo oficial.

Simultaneamente, naquele período, muitos recursos do Ministério da Saúde foram investidos em propagandas para conscientização da população com relação à doença, à forma de contágio e à nova nomenclatura obrigatória. O investimento foi muito grande e pode-se afirmar, pelas frequências obtidas nas análises de textos científicos, que o termo hanseníase teve ampla aceitação pela comunidade científica e pelos autores de artigos sobre a doença.

A pergunta que se apresenta no título deste artigo propõe uma reflexão sobre a eficácia de toda essa mobilização para a mudança na percepção da doença pela população e para melhor compreensão dos aspectos sanitários relativos à hanseníase. O que se pode perceber, considerando o corpus formado para a análise, é que, mesmo no discurso acadêmico-científico, foi necessário que o termo lepra continuasse sendo utilizado, tanto para referenciar o novo termo que estava em processo de implantação quanto para a citação de outros textos, já que essa modificação na terminologia oficial da doença só aconteceu no território brasileiro. O cientista que desejar publicar seu trabalho em revistas estrangeiras precisará utilizar os equivalentes para hanseníase nas outras línguas para que seu trabalho tenha visibilidade e seja compreendido pelos seus pares estrangeiros.

\section{REFERÊNCIAS}

ALVES, I. M. A renovação lexical nos domínios de especialidade. Ciência e Cultura, São Paulo, v. 58, n. 2, p. 32-34, jun. 2006.

AUGER, P. Norme - Normalisation - Normalisation terminologique (Notes de cours). Québec: Université Laval, 1993. 
AULETE DIGITAL. [on-line]. Dicionário Aulete. Rio de Janeiro: Lexicon Editora Digital, 2008. Disponível em: http://www.aulete.com.br/on-line. Acesso em: 19 jan. 2018.

BOULANGER, J. C. Présentation: images et parcours de la socioterminologie. Meta, v. 40, n. 2, p. 194-205, jun. 1995.

BRASIL. Lei no 9.010 de 29 de março de 1995. Disponível em: http://www.planalto.gov.br/ ccivil_03/leis/L9010.htm. Acesso em: 11 dez. 2016.

CABRÉ, M. T. Hacia una teoría comunicativa de la terminología: aspectos metodológicos. La terminología: representación y comunicación. Barcelona: Institut Universitari de Lingüística Aplicada, 1999. p. 129-150.

CABRÉ, M. T. ¿Lenguajes especializados o lenguajes para propósitos específicos? Foro Hispanico: Revista hispanica de Flandes y Holanda, Amsterdam. ed. 26, p. 19-34, ago. 2004.

CIAPUSCIO, G. E. Textos especializados y Terminologia. Barcelona: Institut Universitari de Lingüística Aplicada / Universitat Pompeu Fabra, 2003.

DI DIO, L. J. A. Lançamento oficial da Terminologia Anatômica em São Paulo: um marco histórico para a medicina brasileira. Rev. Assoc. Med. Bras., v. 46, n. 3, p. 191-193, jul./set. 2000.

DIKI-KIDIRI, M. Un enfoque cultural de la terminologia. Debate Terminológico, n. 5, ago. 2009 [não paginado]. Disponível em http://seer.ufrgs.br/index.php/riterm/article/ view/23955 Acesso em: 23 ago. 2018.

DIKI-KIDIRI, M. La diversité dans l'observation de la réalité. In: CABRÉ, M. T. Terminología y modelos culturales. Barcelona: Institut Universitari de Lingüística Aplicada. Barcelona, 1999.

DORES, M. V. P.; TOLEDO, C. V. S. De "lepra" à "hanseníase": Uma análise lexicológica de base sócio-histórica. Diacrítica, v. 32, n. 1, p. 179-208, 2018. Disponível em: http:// diacritica.ilch.uminho.pt/index.php/dia/article/view/124. Acesso em: 10 abr. 2020.

FAULSTICH, E. Planificação linguística e problemas de normalização. Alfa, São Paulo, n. 42 (esp.), p. 247-268, 1998. 
FSP/USP. CID-10. Classificação Estatística Internacional de Doenças e Problemas Relacionados à Saúde. Décima Revisão. Versão 2008. Volume I. Centro Colaborador da OMS para a Classificação de Doenças em Português (Centro Brasileiro de Classificação de Doenças) - Faculdade de Saúde Pública da Universidade de São Paulo/Organização Mundial de Saúde/Organização Pan-Americana de Saúde. Disponível em: http://www. datasus.gov.br/cid10/V2008/WebHelp/cid10.htm. Acesso em: 10 ago 2017.

FREIXA, J. Variació terminològica: anàlisi de la variació denominativa en textos de diferent grau d'especialització de l'àrea de medi ambiente. 2002. Tese (Doutorado) - Universitat de Barcelona, Barcelona, 2002. Disponível em: https://www.tdx.cat/handle/10803/1677. Acesso em: 16 jun. 2021.

GAUDIN, F. Socioterminologie. Une approche sociolinguistique de la terminologie. Rouen: Université de Rouen, 1993.

GAUDIN, F. Socioterminologia: um itinerário bem-sucedido. In: ISQUERDO, A. N., DAL CORNO, G. M. (org.). As ciências do léxico: lexicologia, lexicografia, terminologia. v. VII. Campo Grande: Editora UFMS, 2014.

GLÄSER, R. The problem of style classification in LSP (ESP). Proceedings of the 3rd European Symposium on LSP, Copenhagen, Denmark, 1982.

GRZYBOWSKI, A.; KLUXEN, G.; PÓŁTORAK, K. Gerhard Henrik Armauer Hansen (18411912) - 100 years anniversary tribute. Acta Ophthalmologica, 92, p. 296-300, 2014. Disponível em: https://onlinelibrary.wiley.com/doi/full/10.1111/aos.12159. Acesso em: 30 set. 2017.

GUESPIN, L.; MARCELLESI, J-B. Pour la Glottopolitique. Langages, n. 83, p. 5-34, 1986.

HOFFMANN, L. Característiques dels llenguatges d'especialitat. In: HOFFMANN, L. Lenguatges d'especialitat: Selecció de textos. (Sèrie Monografies, 1). Edició de J. Brumme. Barcelona: Institut Universitari de Lingüística Aplicada, Universitat Pompeu Fabra, 1998. p. 21-69.

HOUAISS. [on-line]. Grande Dicionário Houaiss da Língua Portuguesa. Rio de Janeiro: Instituto Antônio Houaiss, 2009. Disponível em: https://houaiss.uol.com.br/pub/apps/ www/v3-3/html/index.php\#2. Acesso em: 19 jan. 2018.

INTERNATIONAL LEPROSY ASSOCIATION. Dr. Gerhard Armauer Hansen. Disponível em: http://leprosyhistory.org/database/person1. Acesso em 23 set. 2017. 
ISO 15225. Medical devices - Quality management - Medical device nomenclature data structure. International Organization for Standardization, 2010.

ISO 1087. (E/F). Terminology work - Vocabulary - Part 1: theory and application / Travaux terminologiques - Vocabulaire - Partie 1: théorie et application. Genève: International Organization for Standardization, 2000.

KRIEGER, M. G. A face linguística da terminologia. In: KRIEGER, M. G.; MACIEL, A. M. B. Temas de terminologia. Porto Alegre/São Paulo: Ed. UFRGS/Humanitas, 2001.

LINO, M. T.; CHICUNA, A. M.; GRÔZ, A. P.; MEDINA, D. Neologia, terminologia e lexicultura: a língua portuguesa em situação de contacto de línguas. Filologia e linguística portuguesa, v. 12, n. 2, p. 187-201, 2010.

MACIEL, A. M. B. Quais são os rumos da Terminologia no século XXI. In: ISQUERDO, A. N., DAL CORNO, G. M. (org.). As ciências do léxico: lexicologia, lexicografia, terminologia. v. 3. Campo Grande: Editora UFMS, 2007. p. 371-383.

MICHAELIS. [on-line]. Michaelis Dicionário Brasileiro da Língua Portuguesa. São Paulo: Melhoramentos, 2015. Disponível em: http://michaelis.uol.com.br/moderno-portugues/. Acesso em: 19 jan. 2018.

MDH - Ministério dos Direitos Humanos. Hanseníase: Histórico da política de profilaxia da "lepra". Brasília: MDH, 2017. Disponível em: http://www.sdh.gov.br/assuntos/ pessoa-com-deficiencia/programas/hanseniase-1/historico-da-politica-de-profilaxia-da201clepra201d. Acesso em 23 set. 2017.

MURAD, E. Justificação do Projeto de Lei nº 1.624. Diário do Congresso Nacional. Brasília: DCN, 09/11/1991, p. 22485.

OPROMOLLA, P. A. Informação em saúde: a trajetória da hanseníase no Estado de São Paulo, 1800-2005. Tese (Doutorado em Saúde Pública) - Faculdade de Saúde Pública, Universidade de São Paulo, São Paulo, 2007. Disponível em: http://www.teses.usp.br/ teses/disponiveis/6/6132/tde-24102007-151611/pt-br.php. Acesso em: 23 set. 2017.

OPROMOLLA, P. A.; LAURENTI, R. Hansen's disease control in the State of São Paulo: a historical analysis. Rev. Saúde Pública, São Paulo, v. 45, n. 1, p. 195-203, fev. 2011. Disponível em: http://www.scielo.br/scielo.php?script=sci_arttext\&pid=S0034$89102011000100022 \&$ Ing=en\&nrm=iso. Acesso em: 23 set. 2017. 
PANDYA, S. S. The First International Leprosy Conference, Berlin, 1897: the politics of segregation. Hist. cienc. saúde-Manguinhos, Rio de Janeiro, v. 10, supl. 1, p. 161-177, 2003. Disponível em: http://www.scielo.br/scielo.php?script=sci_arttext\&pid=S010459702003000400008\&lng=en\&nrm=iso. Acesso em: 23 set. 2017.

RAJAGOPALAN, K. As políticas linguísticas. D.E.L.T.A, n. 24, v. 1, p. 135-139, 2008.

REY, L. Dicionário de termos técnicos de medicina e saúde. 2. ed. Rio de Janeiro: Guanabara Koogan, 2012.

REYES, E. R. Lepra: asunto de preocupación de salud mundial. Revista Ciencias Médicas, Habana, v. 19, n. 3, p. 421-432, 2013. Disponível em: http://revcmhabana.sld.cu/index. php/rcmh/article/view/617. Acesso em: 23 set. 2017.

SILVA, E. R. A pesquisa em política linguística: histórico, desenvolvimento e pressupostos epistemológicos. Trab. linguist. apl., Campinas, v. 52, n. 2, p. 289-320, dez. 2013. Disponível em: http://www.scielo.br/scielo.php?script=sci_arttext\&pid=S010318132013000200007\&lng=en\&nrm=iso. Acesso em: 10 Abr. 2020.

SPOLSKY, B. Language Management. Cambridge: Cambridge University Press, 2009.

WÜSTER, E. Introducción a la Teoría General de la Terminología y a la Lexicografía Terminológica. Tradução A. Nokerman. Barcelona: Institut Universitari de Lingüística Aplicada/Universitat Pompeu Fabra, 1998 [1979]. 